\title{
Avaliação do efeito da castração e de variáveis ambientais sobre a marcação por urina e fezes em gatos (Feliscatus)
}

\author{
Evaluation of neutering and environmental factors \\ in urine and feces marking behavior in domestic cats (Felis Catus)
}

Raquel Calixto ${ }^{1} \&$ Heloisa Justen ${ }^{2}$

\begin{abstract}
RESUMO
A marcação territorial é o comportamento felino de maior queixa por parte do proprietário. É manifestado por felinos jovens na puberdade, sendo mais comum em machos. A castração é o tratamento mais usado. Sendo a marcação o comportamento indesejável mais comum na espécie felina, é importante para o clínico veterinário alertar aos proprietários sobre sua ocorrência, dando-lhes orientações para que tal comportamento seja prevenido. O objetivo desse trabalho é traçar o perfil dos gatos com marcação submetidos à castração e, averiguar a resposta à gonadectomia. Os dados foram obtidos de entrevistas com 24 proprietários de gatos, realizadas antes e 15, 30, 45 e 60 dias após a castração. Os métodos estatísticos usados foram o Quiquadrado e Mc Nemar. Dos 24 felinos, 79\% eram machos, 71\% era sem raça definida e, 54\% tinham entre seis meses e um ano de idade. A castração foi eficaz na redução das marcações em $83 \%$ dos animais. O período de maior resposta foi aos 15 dias após a cirurgia. $\mathrm{O}$ estudo demonstrou que castração é um procedimento eficaz na redução das marcações por urina e fezes em animais inteiros, mas que fatores ambientais influenciam para perpetuação do comportamento mesmo após a gonadectomia.
\end{abstract}

Descritores: felino, gonadectomia, comportamento, marcação territorial.

\section{ABSTRACT}

Marking is the most common behavior problem in cats, frequent in young cats from the onset of puberty. Most cases occur in male cats. Castration is the most used treatment. The goal of this study was to describe the profile of cats submitted to castration that exhibit marking behavior and investigate the effect of gonadectomy in these cats. The data of this study was collected from interviews with 24 cat owners. The interviews were made before and at 15, 30, 45, 60 days after the surgery. Statistic methods used were the $\mathrm{X}^{2}$ test and the Mc Nemar test. Of 24 cats, $79 \%$ were male, $71 \%$ were of mixed breeding and $54 \%$ were aged from 6 months to 1 year. Castration was efficient to reduce marking behaviour in $83 \%$ of the cats. The best response to gonadectomy occurred after 15 days. This study showed that castration is efficient in reducing marking behavior, althought enviromental factors have influence on the maintenance of this behavior after gonadectomy.

Key words: feline, neutering, behavior, marking. 


\section{INTRODUÇÃO}

A eliminação felina é compreendida por duas manifestações distintas, a marcação territorial e a eliminação inapropriada. A eliminação inapropriada é a recusa do animal em utilizar o seu local de eliminação habitual, seja a vasilha sanitária, a área externa da residência, dentre outros, e está ligada tanto à micção quanto à defecação [8]. A marcação territorial é um comportamento social normal, sendo um meio de comunicação entre os membros de uma população [1,6,16]. A marcação é comum no início da maturidade sexual do macho, sendo manifestada com maior frequiência por este, embora as fêmeas marquem por ocasião do estro [23]. A marcação não é um distúrbio, mas é encarada como tal quando exercida em convívio com seus donos, tornando-se intolerável, sendo uma das principais causas de abandono e eutanásia em alguns países [21]. Ela pode ser incitada por alterações ocorridas no ambiente que provoquem ansiedade no gato, como grande número de animais, presença de novos gatos, dentre outros [3,18]. A marcação envolve uma postura típica, descrita pela posição em estação e cauda em movimentos serpentiformes, emitindo pequenos jatos de urina em borrifo. Geralmente, os alvos são superfícies verticais, podendo ocorrer em superfícies horizontais, ligada também às fezes e à urina sem borrifo $[1,3,5,8,20]$. Na eliminação inapropriada, o felino não exibe nenhuma postura típica [20]. A castração é o método mais indicado para o tratamento da marcação territorial, removendo dessa forma, a influência hormonal [3,7,11,12,15,17].

Este estudo visa traçar o perfil dos gatos submetidos à castração eletiva, que marcam, segundo o sexo, raça, idade; caracterizando a marcação territorial segundo o tipo (urina e/ou fezes), a frequiência, a postura do animal, os locais-alvos, o uso do local de eliminação habitual; avaliar a resposta à castração quanto ao grau de melhora e tempo de melhora das marcações; e avaliar as mudanças ocorridas no ambiente.

\section{MATERIAIS E MÉTODOS}

Os animais incluídos neste estudo são da espécie felina (Felis catus) de ambos os sexos, provenientes da Clínica Veterinária Gatos e Gatos Vet. e do Instituto Municipal Veterinário Jorge Vaitsman, localizados na cidade do Rio de Janeiro. Foram selecionados entre os anos 2003 e 2004, inicialmente, 62 felinos a partir da triagem pré-operatória para realização de orquiectomia e ovariossalpingo-histerectomia. Desses felinos, a marcação foi identificada em 24 animais, sendo 19 machos e 5 fêmeas. A faixa etária variou entre seis meses e 13 anos, com média de 2,3 anos $( \pm 2,65)$. Sendo todos os animais hígidos, e nenhum estava sob terapia comportamental no momento da seleção e durante a realização do estudo.

Os proprietários dos animais selecionados foram esclarecidos quanto ao objetivo e metodologia da pesquisa antes do início desta. E, então, submetidos a uma primeira entrevista por ocasião da castração, onde responderam um questionário de perguntas fechadas com respostas em múltipla escolha, o qual avaliou o comportamento do gato antes da castração. Este questionário abrangeu 12 perguntas para identificação das características da marcação territorial como a presença de eliminação fora do local habitual, o tipo de eliminação (urina, fezes, urina e fezes), as características (superfície vertical ou horizontal, micção em borrifo ou não, pequeno ou grande volume, movimento da cauda, farejar o local), a freqüência, a duração do comportamento, e os locais-alvos da eliminação. E ainda perguntas para identificação de fatores possivelmente envolvidos na marcação territorial como o número de gatos da residência, a posição social do felino avaliado (dominante ou dominado), a presença de agressividade, e ainda, histórico prévio de distúrbio do trato urinário inferior (DTUI) e mudanças na rotina da residência (aquisição de novos animais, presença de crianças, mudança de móveis, mudança de residência, viagens, etc).

Para avaliar a eficácia da castração quanto à melhora total ou a redução das marcações, os proprietários foram submetidos a outras entrevistas, realizadas por telefone, 15, 30, 45 e 60 dias após a castração. Essa constava de um questionário que apresentava indagações sobre a melhora total, sobre o tipo, as características, a frequiência e os locais-alvos da marcação, quando essa ainda persistia. A melhora total significa que o felino não marcou mais o território, enquanto que, a melhora parcial é qualificada como uma redução na frequiência das marcações.

Os dados coletados foram armazenados em banco de dados criado através do software SPSS 10.0 e, posteriormente processados. Os testes Qui-quadrado $\left(\mathrm{x}^{2}\right)$ e McNemar foram utilizados para a análise dos resultados, fixando um nível de significância em 5\%. 


\section{RESULTADOS}

O comportamento dos animais deste estudo foi analisado no intuito de confirmar a presença da marcação territorial, tomando como base as variantes: presença de eliminação fora do local habitual, tipo (urina e/ou fezes), características (superfície vertical ou horizontal, micção em borrifo ou não, pequeno ou grande volume, movimento da cauda, farejar o local), frequiência, duração, e locais-alvos da eliminação indesejada. Os dados foram coletados de 62 felinos, sendo 31 machos e 31 fêmeas. Trinta e oito por cento (24/62) deles apresentaram marcação territorial, sendo $79 \%$ (19/24) machos e apenas 21\% (5/24) fêmeas (Figura 1). Denotando uma frequiência significativamente maior de tal comportamento em felinos machos $(\mathrm{P}<0,01)$.

Quanto à raça dos animais, 17 dos 24 gatos eram sem raça definida (SRD), seis eram raça persa e apenas um era da raça exótico. Quanto à idade, 13 gatos estavam na faixa entre seis meses e um ano, dez gatos estavam na faixa entre dois e cinco anos e, apenas um gato tinha mais de dez anos. A idade variou de seis meses até 13 anos, cuja média é de 2,3 anos $( \pm 2,65)$.

Segundo o motivo para castração relatado pelos proprietários, $15(62,5 \%)$ proprietários responderam que era para cessar as marcações territoriais; seis $(25 \%)$ responderam que era para evitar fugas, brigas e acidentes fora de suas residências em função do acesso ao ambiente externo da mesma; apenas dois $(8,3 \%)$ relataram a prevenção de prenhez como justificativa e; somente um $(4,2 \%)$ proprietário de felino fêmea desejava reduzir a agressividade em relação a outros animais com a castração.

Avaliando o tipo de marcação antes da castração, 14 dos 19 felinos machos $(73,7 \%)$ e três dos cinco felinos fêmeas $(60 \%)$ apresentaram marcação ligada somente à urina; cinco dos 19 machos (26,3\%) e dois $(40 \%)$ das cinco fêmeas apresentaram marcação ligada tanto à urina quanto às fezes. Nenhum gato apresentou marcação ligada somente às fezes. Em relação ao uso do local de eliminação, $17(89,5 \%)$ dos 19 gatos machos e todas as cinco fêmeas $(100 \%)$ demonstraram usar normalmente o local de eliminação. Somente dois $(10,5 \%)$ dos 19 machos apresentaram uma redução ou ausência no uso do local de eliminação.

Apresentaram marcação em superfícies verticais $68,4 \%$ (13/19) dos felinos machos e $20 \%$ (1/5) dos felinos fêmeas estudados; $31,6 \%$ (6/19) dos machos e $80 \%$ (4/5) das fêmeas marcavam em superfícies horizontais. Eliminavam um pequeno volume de urina 73,7\% (14/19) dos gatos machos e 60\% (3/5) das fêmeas, enquanto que 26,3\% (5/19) dos machos e $40 \%$ (2/5) das fêmeas eliminavam um grande volume de urina. Quarenta e sete por cento (9/19) dos machos e $20 \%$ (1/5) das fêmeas demonstraram balançar a cauda durante a marcação e, apenas $21,1 \%$ (4/ 19) machos farejavam o local-alvo antes e/ou depois do ato, tal comportamento não foi observado em nenhuma fêmea.

Relacionando os gatos avaliados com o número de felinos na residência (Figura 2), pode-se observar que $67 \%$ (16/24) dos felinos com marcação territorial pertenciam a residências com mais de um gato e, somente $33 \%(8 / 24)$ pertenciam a residências com um único gato.

Quanto à dominância, 54\% (13/24) dos felinos mostraram comportamento dominante em relação a

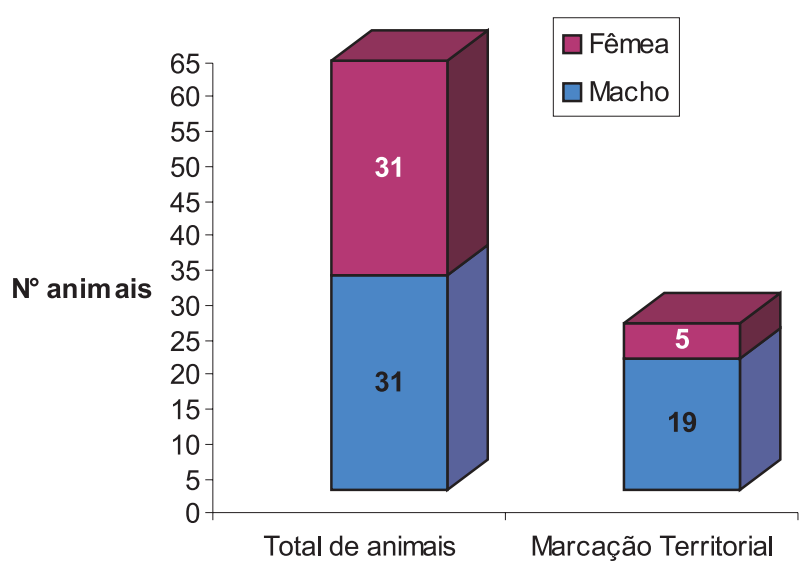

Figura 1. Correlação dos números de animais com marcação territorial segundo o sexo com o número total de animais avaliados. Estudo realizado em 2003 e 2004, na Clínica Veterinária Gatos \& Gatos Vet. e no Instituto Municipal Veterinário Jorge Vaitsman.

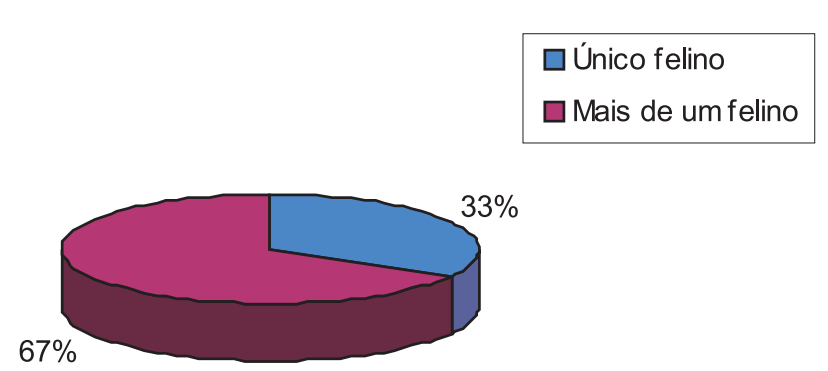

Figura 2. Distribuição dos animais através dos valores percentuais segundo o número de animais da residência. Estudo realizado em 2003 e 2004, na Clínica Veterinária Gatos \& Gatos Vet. e no Instituto Municipal Veterinário Jorge Vaitsman. 
outros felinos de seu convívio ou mesmo ao proprietário quando o felino avaliado era único na residência, enquanto que $29 \%$ (7/24) se mostraram submissos. Sendo que, $17 \%$ (4/24) felinos não demonstraram nenhuma posição social aparente ao proprietário. Em relação ao temperamento agressivo dos animais neste estudo, somente um $(5,3 \%)$ dos 19 machos foi considerado agressivo por seu proprietário. Nenhuma fêmea foi considerada agressiva.

Apenas dois dos 19 machos apresentaram histórico de DTUI, porém sem manifestação clínica no momento da avaliação, tendo estes idade não superior a dois anos.

Em relação à ocorrência de alguma mudança na rotina da residência desde o aparecimento da marcação territorial, como adoção de outro felino ou nascimento de filhotes, presença de recém-nascidos, mudanças de horário, falecimento de algum animal, viagens, dentre outras, $46 \%$ (11/24) dos proprietários relataram ter havido alguma mudança em suas rotinas.

$\mathrm{Na}$ análise do comportamento realizada aos 15 dias após a castração (Tabela 1), 54,2\% (13/24) dos gatos melhoraram totalmente em relação ao distúrbio de marcação territorial, 29,2\% (7/24) melhoraram parcialmente e, 16,7\% (4/24) não apresentaram nenhuma melhora. Houve diferença significativa no período de 15 dias após a castração, onde os animais responderam de forma positiva, cessando as marcações, tanto relacionadas à urina $(\mathrm{P}<0,05)$, quanto à urina e fezes $(\mathrm{P}<0,01)$. Aos 30 dias após a castração, $75 \%(18 / 24)$ dos gatos apresentaram melhora total, $16,7 \%(4 / 24)$ apresentaram melhora parcial e, somente $8,3 \%(2 / 24)$ dos gatos não apresentaram nenhuma melhora. Pode-se afirmar que entre os períodos antes da castração e 30 dias após, a parada das marcações foi significativa tanto relacionada somente à urina $(\mathrm{P}$ $<0,01)$ quanto à urina e fezes $(\mathrm{P}<0,01)$. Comparandose a melhora da marcação territorial relacionada somente à micção entre os períodos de 15 e 30 dias, houve diferença significativa entre esses períodos $(\mathrm{P}$ $<0,01)$. O que não ocorreu na marcação relacionada à urina e fezes entre esses mesmos períodos. Aos 45 dias, porcentagem de animais com melhora total das marcações aos 45 dias permaneceu a mesma. Já quanto à melhora parcial, 20,8\% (5/24) dos gatos apresentaram redução na freqüência da marcação territorial e, somente $4,2 \%$ (1/24) dos gatos não apresentaram melhora nesse período. Novamente, houve melhora estatisticamente relevante entre os comportamentos antes e após 45 dias de castração relacionados à urina $(\mathrm{P}<0,01)$ e à urina e fezes $(\mathrm{P}<0,01)$. Também houve diferença significativa entre os períodos de 15 e 45 dias no comportamento relacionado somente à urina $(\mathrm{P}<0,05)$, mas não relacionado à urina e fezes. Entre os períodos de 30 e 45 dias, a diferença não foi relevante tanto para o comportamento relacionado somente à urina, quanto à urina e fezes. Aos 60 dias após a castração, a porcentagem de gatos com melhora total declinou para 70,8\% (17/24). Quanto à melhora parcial, $12,5 \%$ (3/24) dos gatos apresentaram redução das marcações. A mesma porcentagem de gatos $(12,5 \%)$ não apresentou melhora das marcações nesse período, denotando a recidiva das marcações em três felinos. Os comportamentos relacionados à micção antes da castração e 60 dias após esta tiveram diferenças significativas $(\mathrm{P}<0,01)$ e, também os comportamentos relacionados à micção e defecação $(\mathrm{P}<$ $0,01)$. Entre períodos, a única diferença significativa foi para o comportamento relacionando somente à

Tabela 1. Distribuição 24 dos animais com marcação territorial segundo os períodos de avaliação e sexo, quanto à mudança de comportamento após a castração.

\begin{tabular}{|c|c|c|c|c|c|c|c|c|}
\hline \multirow{4}{*}{$\begin{array}{l}\text { Mudança de } \\
\text { Comportamento }\end{array}$} & \multicolumn{8}{|c|}{ Períodos de Avaliação } \\
\hline & \multicolumn{2}{|c|}{15 dias } & \multicolumn{2}{|c|}{30 dias } & \multicolumn{2}{|c|}{45 dias } & \multicolumn{2}{|c|}{60 dias } \\
\hline & \multicolumn{8}{|c|}{ Animais } \\
\hline & Macho $(n=19)$ & Fêmea $(n=5)$ & Macho $(n=19)$ & Fêmea $(n=5)$ & Macho $(n=19)$ & Fêmea $(n=5)$ & Macho $(n=19)$ & Fêmea $(n=5)$ \\
\hline Melhora Total & $11(57,9 \%)$ & $2(40 \%)$ & $15(78,9 \%)$ & $3(60 \%)$ & $15(78,9 \%)$ & $3(60 \%)$ & $14(73,7 \%)$ & $3(60 \%)$ \\
\hline Melhora Parcial & $4(21,1 \%)$ & $3(60 \%)$ & $2(10,5 \%)$ & $2(40 \%)$ & $3(15,8 \%)$ & $2(40 \%)$ & $2(10,5 \%)$ & $1(20 \%)$ \\
\hline Nenhuma Melhora & $4(21,1 \%)$ & - & $2(10,5 \%)$ & - & $1(5,3 \%)$ & - & $3(15,8 \%)$ & $1(20 \%)$ \\
\hline
\end{tabular}

Estudo realizado em 2003 e 2004, na ClínicaVeterinária Gatos \& Gatos Vet. e no Instituto Municipal Veterinário Jorge Vaitsman, com 24 felinos domésticos, sendo 19 machos e cinco fêmeas. Melhora total - nenhuma marcação; melhora parcial - redução na frequiência das marcações. 
urina entre 15 e 60 dias $(\mathrm{P}<0,05)$. Para os períodos entre 15 e 60 dias para comportamento relacionando à urina e fezes, bem como, para os períodos entre 30 e 60 dias e, 45 e 60 dias, tanto no comportamento relacionado à urina, quanto à urina e fezes, não houve diferença estatisticamente relevante.

Portanto, tomando como base não somente os animais que cessaram totalmente as marcações, mas também aqueles que apresentaram redução da freqüência (melhora parcial), pode-se dizer que 83\% dos gatos responderam de forma positiva à gonadectomia.

Após 15 dias da castração, 45,8\% dos gatos estudados permaneceram com distúrbio de marcação, sendo que dez $(90,9 \%)$ marcavam somente através da urina, e apenas um $(9,1 \%)$ marcava através da urina e das fezes (Figura 3). Aos 30 dias de castração, esse número declinou para $25 \%$. Sessenta e sete $(4 / 6)$ por cento dos gatos apresentavam a marcação relacionada apenas à urina, $16,5 \%$ (1/6) estavam relacionados somente às fezes e $16,5 \%$ (1/6) relacionados tanto à urina quanto às fezes. Aos 45 dias após a castração, não houve alteração dessa porcentagem, e ainda $67 \%$ (4/6) dos gatos apresentaram a marcação ligada apenas à urina, e 33\% (2/6) ligados à urina e às fezes. Aos 60 dias após a castração, 29,2\% dos felinos continuavam com distúrbio de marcação, $57 \%$ (4/7) apresen- tavam marcação através de urina; 28,5\% (2/7) apresentaram marcação somente relacionada às fezes, e $14,5 \%(1 / 7)$ relacionados à urina e fezes.

Considerando as mudanças ocorridas na rotina dos proprietários e/ou dos animais aos 15 dias de castração, em 8,3\% (2/24) das residências houve mudança da rotina caracterizada pela adoção de outro animal; em 4,2\% (1/24) a mudança se deu em função de criança recém-nascida, e novamente em 8,3\% (2/ 24) houve outras mudanças na rotina, como pequena viagem e obra. Já aos 30 dias, em 4,2\% (1/24) das residências houve a adoção de outro animal, e em $12,5 \%$ (3/24) houve outras mudanças na rotina. Aos 45 dias, um número maior (6/24) de felinos sofreu mudanças em seu ambiente quando comparado aos 30 dias após a castração (4/24), em uma residência $(4,2 \%)$ a mudança se referiu à adoção de outro felino, em outra $(4,2 \%)$ a mudança ocorreu devido à presença de criança recém-nascida. Em uma residência $(4,2 \%)$, o proprietário relatou mudança de horário de trabalho, e em três residências $(12,5 \%)$ as mudanças ocorreram por outros motivos não especificados. Aos 60 dias de castração, somente 12,5\% (3/24) dos proprietários relataram mudanças na rotina da residência, $8,3 \%(2 / 24)$ se referiam à adoção de um novo felino, e em $4,2 \%(1 / 24)$ referiam-se à chegada de criança recém-nascida.

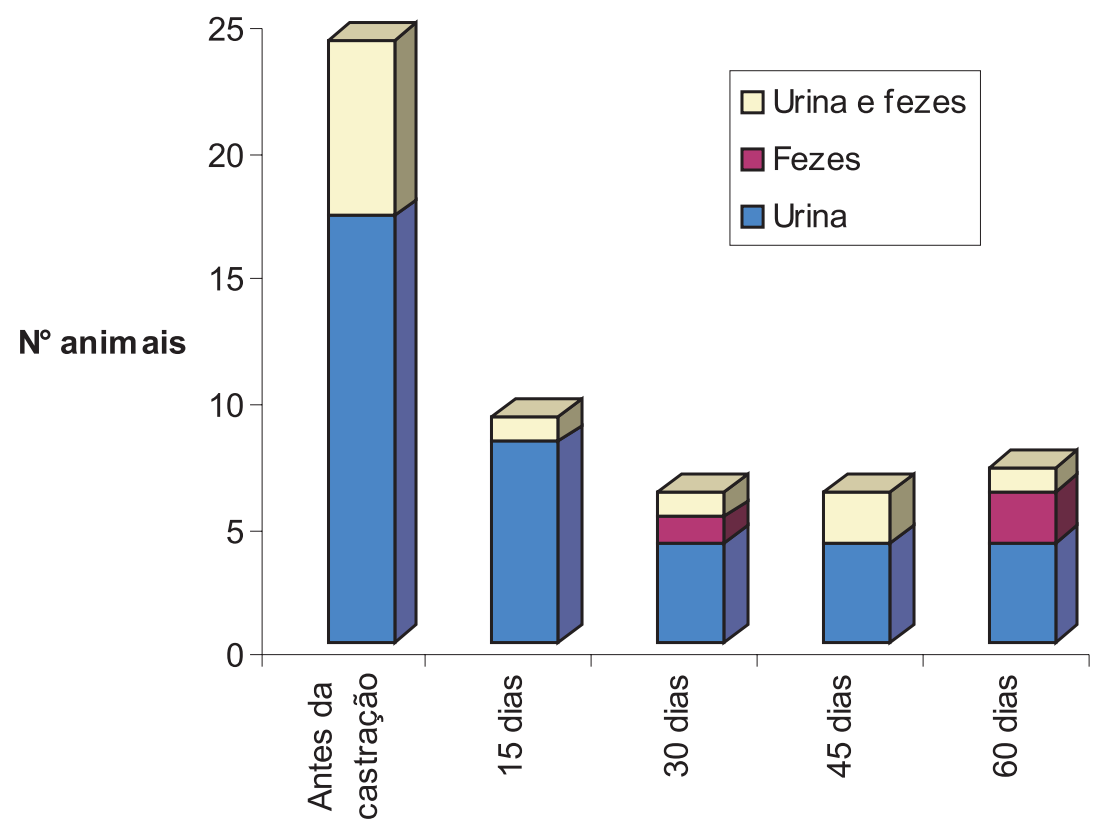

Figura 3. Distribuição dos 24 animais segundo os períodos de avaliação antes e após a castração quanto ao tipo de marcação territorial. Estudo realizado em 2003 e 2004, na Clínica Veterinária Gatos \& Gatos Vet. e Instituto Municipal Veterinário Jorge Vaitsman. 
Vinte e nove por cento (7/24) dos felinos submetidos à castração neste estudo continuaram apresentando a marcação territorial após 60 dias. Desses felinos, cinco $(71,4 \%)$ eram machos e dois $(28,6 \%)$ eram fêmeas. Um macho apresentou melhora total dos 15 aos 45 dias de castração, o que significa que as marcações cessaram por completo, entretanto, aos 60 dias o animal voltou a marcar a residência somente com defecações, neste intervalo foi detectada alteração na rotina do animal representada pela mudança de ambiente (novo lar), motivo pelo qual o animal voltou a marcar. Outro macho melhorou totalmente aos 30 dias após a castração, mas voltou a marcar através de micção aos 60 dias. Segundo avaliações do ambiente, o animal vivia em colônia com 37 felinos, motivo de sua ansiedade e estresse. Um macho cessou totalmente a marcação territorial logo após a castração, todavia desenvolveu um distúrbio ligado à eliminação inapropriada, representado, neste caso, pela aversão ao substrato, em virtude da má higienização da vasilha sanitária, o que levava o animal a urinar e defecar ao lado da vasilha sanitária. Outro felino desenvolveu preferência por substrato, embora tenha melhorado com relação à marcação territorial logo após a castração, o animal permaneceu defecando e urinando sobre o piso de um único local da residência. Apenas um felino macho não apresentou nenhum sinal de melhora durante todos os períodos avaliados, havendo uma piora refletida no aumento da frequiência das marcações aos 15 e 30 dias. Através da análise de seu ambiente, pode-se afirmar que o animal sofria de grande ansiedade relacionada à proprietária (sendo esta também alvo das marcações) e aos novos felinos introduzidos em seu ambiente, inclusive filhotes recémnascidos. Uma fêmea não apresentou nenhuma melhora aos 60 dias, e outra fêmea apresentou somente uma melhora parcial durante todos os períodos avaliados denotado apenas pela redução na frequiência das marcações. Não foi detectado nenhum fator de ansiedade ou estresse na rotina desses animais.

\section{DISCUSSÃO}

Da população submetida à castração eletiva avaliada neste trabalho, uma parte significativa apresentava marcação territorial, conforme relatado em trabalho anterior [12]. Os dados dessa pesquisa denotam que a ocorrência da marcação em animais intei- ros é maior em felinos machos do que em fêmeas, fato esse também observado em diversos outros estudos $[6,12,13,19,24]$.

Neste trabalho foi constatado que a maioria dos animais com marcação e outro distúrbio de eliminação são de raça mestiça. $\mathrm{O}$ mesmo foi encontrado em pesquisa anterior [8], embora tal comparação se faça em populações de países e realidades diferentes.

A maioria dos gatos avaliados se apresentou em idade pré-púbere ou ainda no início ou em plena da maturidade sexual. É nessa fase onde há maior frequiência no aparecimento da marcação, influenciada pelo estímulo androgênio fortemente presente [12].

Uma pesquisa concluiu que grande parte dos proprietários procura ajuda do médico veterinário para tratamento de seus animais com marcação [2]. Neste estudo, percebeu-se o oposto, muitos proprietários escolheram a castração como um método de tratamento para as marcações sem qualquer orientação do médico veterinário. Isso reflete, talvez, que os proprietários tomam tal decisão baseados em informações adquiridas na prática diária ou de fontes informais de comunicação.

As características da marcação no que se refere ao tipo de produto eliminado (urina e/ou fezes), ao volume de urina emitido, à postura tomada pelo animal no ato da marcação, ao movimento serpentiforme da cauda, e ao ato de farejar o local a ser marcado, já foram enfaticamente destacadas por diversos estudos anteriores [3-5,9,10,14,17,19,22]. Todos os gatos avaliados para marcação demonstraram sempre mais de uma dessas características, permitindo dessa forma verificar facilmente a presença da marcação territorial. Essas características auxiliam no diagnóstico da marcação, bem como o uso normal do local de eliminação habitual. Tal observação é parte fundamental no diagnóstico diferencial para o distúrbio de eliminação inapropriada, onde muitas vezes a marcação territorial é erroneamente apontada como problema [8].

A marcação territorial ocorre mais comumente em residências com vários gatos [9,19]. Esse estudo pôde constatar o mesmo fato, isto é, quando considerando o número de felinos na residência, observou que a grande maioria dos gatos com marcação convivia com um ou mais felinos. Portanto, percebe-se que a interação dos gatos avaliados com os outros residentes na mesma casa é importantíssimo fator no desenvolvimento da marcação territorial. 
A motivação para marcação envolve um comportamento, cuja conotação, sempre comunicativa, pode ser territorial, sexual ou agonista entre os membros de uma população, denotando, desta forma, uma interação competitiva ou de dominância [3,4]. E essa relação pode ainda envolver uma agressão ativa ou passiva [22]. Neste estudo, mais da metade dos gatos mostrou ser dominante segundo observação de seus proprietários, todavia apenas um animal demonstrou ser agressivo.

Avaliando-se o histórico de doença do trato urinário inferior (DTUI) nos felinos estudados, a maioria dos gatos não exibiu tal histórico. Isso sugere que o DTUI não exerce influência no desenvolvimento da marcação territorial, fato este levantado em trabalho anterior [25].

Mudanças ocorridas na rotina e no ambiente de convívio dos felinos podem causar estresse e ansiedade, motivos pelos quais as marcações, comumente, são iniciadas [14,24]. Nessa pesquisa, quase metade dos proprietários entrevistados revelou que houve alguma mudança na rotina de seus gatos antes da castração. Todavia, eles não acreditaram que tais mudanças influenciaram seus animais quanto à marcação territorial. Isso se confirmou quando as marcações territoriais foram solucionadas após a castração em quase metade dos casos, denotando que as mudanças ocorridas antes dessa, realmente não tinham influência direta na manifestação desse comportamento.

A castração foi efetiva na redução (diminuição da freqüência) ou cessação das marcações territoriais em todos os períodos avaliados. Entretanto, o período de melhor resposta foi após 15 dias da castração, denotando uma resposta imediata. Esse fato foi anteriormente observado [11]. Em outro trabalho verificou-se que somente $10 \%$ dos machos e $5 \%$ das fêmeas persistiam com a marcação territorial após a castração [12]. Isso pôde ser constatado em relação aos machos nesse estudo. Todavia, o mesmo não ocorreu com as fêmeas, pouco menos da metade delas persistiram com a marcação territorial após a castração. Acredita-se que, essa grande diferença na porcentagem de fêmeas em relação ao trabalho citado, seja devido à sua pequena amostragem na população avaliada.

É sabido que o estímulo hormonal tanto de machos quanto de fêmeas é o mais importante no desenvolvimento da marcação territorial, contudo não é o único. Nesta pesquisa, a castração foi eficaz na resolução imediata do problema em mais da metade dos animais em 60 dias. Não obstante, sete gatos não apresentaram melhora do distúrbio. Constatou-se que três desses eram submetidos a alguma situação estressante em sua rotina, que lhes causavam grande ansiedade, sendo justificativa para a continuidade das marcações. Esse é um fator predisponente que já foi avaliado em outros estudos $[4,12,14]$. Duas fêmeas também não responderam à castração, nestes casos não foi detectada nenhuma alteração em suas rotinas que justificassem tal persistência.

Outros dois machos cessaram a marcação territorial e desenvolveram eliminação inapropriada. Embora, seus proprietários relatassem nas entrevistas que alteração no comportamento continuava, foi possível diferençar a marcação territorial da eliminação inapropriada através de informações adicionais fornecidas por eles. Portanto, apesar desses animais terem sido caracterizados neste estudo como não responsivos à castração, vale ressaltar que a marcação territorial não era mais o distúrbio de eliminação presente.

\section{CONCLUSÃO}

A castração foi um procedimento eficaz na redução das marcações territoriais em mais da metade dos animais. Se essa pesquisa pode ser usada para formular um prognóstico para os gatos com marcação territorial submetidos à castração, é esperado que a melhora do comportamento ocorra em 15 dias após gonadectomia tanto em machos quanto em fêmeas.

Sabendo que fatores ambientais influenciam na manifestação desse comportamento felino, vale salientar que para aqueles animais, cuja influência androgênica é cessada pela castração, o ambiente onde vivem e, as relações sociais existentes dentro do grupo devem ser melhor avaliados. Isso permitirá a correção de possíveis erros de manejo e, principalmente, detectar as causas de estresse e ansiedade.

A orientação de um profissional torna-se importante à medida que as alterações de comportamento podem ser tratadas e antes prevenidas, impedindo assim que o animal seja erroneamente punido ou mesmo abandonado ou ainda condenado à eutanásia por um comportamento absolutamente natural para o felino. 


\section{REFERÊNCIAS}

1 Beaver B. 1980. Feline communicative behavior. In: Veterinary Aspects of Feline Behavior. St. Louis: The C. V. Mosby Company, pp. 54-73.

2 Bergman L., Hart B.L., Bain M. \& Cliff K. 2002. Evaluation of urine marking by cats as a model for understanding veterinary diagnostic and treatment approaches and client attitudes. Journal of American Veterinary Medical Association. 221: $1282-1286$.

3 Borchelt P.L. 1991. Cat elimination behavior problems. The Veterinary Clinics of North America: Small Animal Practice. 21: 257-264.

4 Borchelt P.L. \& Voith V.L. 1986. Elimination behavior problems in cats. The Compendium on Continuing Education. 8: 197-207.

5 Cooper L.L. 1997. Feline inappropriate elimination. The Veterinary Clinics of North America: Small Animal Practice. 27 : 569-600.

6 Cooper L. \& Hart B.L. 1992. Comparison of diazepam with progestin for effectiveness in suppression of urine spraying behavior in cats. Journal of American Veterinary Medical Association. 200: 797-801.

7 Halip J.W., Luescher U.A. \& Mckeown D.B. 1992. Inappropriate elimination in cats, Part 1. Feline Practice. 20:17-21.

8 Halip J.W., Vaillancourt J.P. \& Luescher U.A. 1998. A descriptive study of 189 cats engaging in inappropriate elimination behaviors. Feline Practice. 26: 18-21.

9 Hart B. L. 1980. Objectionable urine spraying and urine marking in cats: evaluation of progestin treatment in gonadectomized males and females. Journal of American Veterinary Medical Association. 177: 529-533.

10 Hart B.L. 1996. Behavioral and pharmacologic approaches to problem urination in cats. The Veterinary Clinics of North America: Small Animal Practice. 26: 651-658.

11 Hart B.L. \& Barret R.E. 1973. Effects of castration on fighting, roaming, and urine spraying in adult male cats. Journal of American Veterinary Medical Association. 163: 290-292.

12 Hart B.L. \& Cooper L. 1984. Factors relating to urine spraying and fighting in prepubertally gonadectomized cats. Journal of American Veterinary Medical Association. 184: 1255-1258.

13 Hart B.L., Eckstein R.A., Powell K.L. \& Dodman N.H. 1993. Effectiveness of buspirone on urine spraying and inappropriate urination in cats. Journal of American Veterinary Medical Association. 203: 254- 258.

14 Horwtiz D.F. 1997. Behavioral and environmental factors associated with elimination behavior problems in cats: a retrospective study. Applied Animal Behaviour Science. 52: 129-137.

15 Houpt K. 1991. Housesoiling: Treatment of a common feline problem. Veterinary Medicine. 86: 1000-1006.

16 Landsberg G. 1996. Feline behavior and welfare. Journal of American Veterinary Medical Association. 208: 502-505.

17 Nielson J.C. 2003. Feline house soiling: elimination and marking behaviors The Veterinary Clinics of North America Small Animal Practice. 33: 287-301.

18 Nielson J.C. 2004. Thinking outside the box: feline elimination. Journal of Feline Medicine and Surgery. 6: 5-11.

19 Olm D.D. \& Houpt K. 1988. A. Feline house-soiling problems. Applied Animal Behaviour Science. 20: 335-345.

20 Overall K.L. 1997. Feline Elimination Disorders. In: Overall K.L. \& Duncan L.L (Eds). Clinical Behavioral Medicine for Small Animals. St Louis: Mosby Inc., pp.160-194.

21 Overall K.L. 1998. Diagnosing feline elimination disorders. Veterinary Medicine. 93: 350-362.

22 Overall K.L. 1998. Tracing the roots of feline elimination disorders to aggression. Veterinary Medicine. 93: 363-366.

23 Pageat P. \& Gaultier E. 2003. Current research in canine and feline pheromones. The Veterinary Clinics of North America - Small Animal Practice. 33: 187-211.

24 Pryor P.A., Hart B.L, Bain M.J. \& Cliff K.D. 2001. Causes of urine marking in cats and effects of environmental management on frequency of marking. Journal of American Veterinary Medical Association. 219: 1709-1713.

25 Tynes V.V., Hart B.L., Pryor P.A., Bain M.J., Locksley L. \& Messam. 2003. Evaluation of the role of lower urinary tract disease in cats with urine-marking behavior. Journal of American Veterinary Medical Association. 223: 457-461.

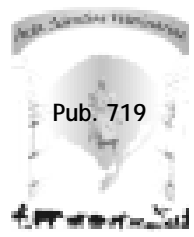

